\title{
Relationship Between Obesity and Periodontal Disease after Minimally Invasive Sleeve Gastrostomy
}

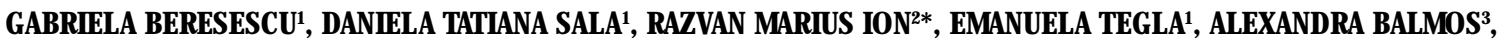 \\ ADINA COSARCA ${ }^{1}$, ALINA ORMENISAN ${ }^{1}$ \\ 'University of Medicine, Pharmacy, Science and Technology Targu Mures, 38 Gh. Marinescu, 540139, Tirgu Mures, Romania \\ ${ }^{2}$ County Emergency Clinical Hospital, 50 Gh. Marinescu, 540125, Tirgu Mures, Romania \\ 3Private Practice, 251 Decembrie 1918, 540125, Tirgu Mures, Romania
}

\begin{abstract}
Obesity is a complex and multifactorial disease. Its relationship with periodontal disease and other chronic diseases is well documented but the underlying mechanism is under investigation. It is quite difficult to say whether obesity predisposes an individual to periodontal disease or periodontal disease affects lipid metabolism, or both. The purpose of the study consists in evaluating the periodontal clinical parameters in obese patients diagnosed with chronic periodontitis, before and after surgical treatment of obesity through the procedure called gastric sleeve Our study consists of a group of 38 patients diagnosed with morbid obesity who were surgically treated by gastric sleeve surgery at the Surgery Department II of the County Emergency Clinical Hospital Targu Mures. Patients with pre-operative and psot-operative examination at 3 months and 6 months respectively in which either periodontal index were index of plaque, index of probing depth and index of bleeding on probing. Correlations between parondontal clinical indexes (PD, PI, BOP) were calculated before and after gastric sleeve at 3 and 6 months respectively. The bleeding on probing index (BOP) reveals a complete decrease in postoperative bleeding time. Patients at 3 months experience minor bleeding during testing and no longer showing bleeding at 6 months. The results provide evidence that there is a link between obesity and periodontitis, however the risk factors that aggravate these diseases should be clarified to elucidate the direction of this association.
\end{abstract}

Keywords: obesity, periodontal disease, lipid metabolism, gastric sleeve

Obesity is one of the most visible, yet neglected public health problems, the World Health Organization (WHO) observed in its report in 2002, when it pointed out that globesity is more widespread than malnutrition. In developed countries, obesity is considered to occupy the third place, after smoking and high blood pressure, as a risk factor for early death and the development of disabilities [1]. Sedentarism, unhealthy diet and intense stress exposure contribute to the increasing number of obese individuals [2]. Autoimmunity can also trigger diet-related pathological states, which also represent a recent health problem [3]. Appropriate diet, rich in fruits and vegetables, having antioxidant capacity, can decrease the incidence of associated cardiovascular pathology, which is very common in obesity and related diabetes [4].

The first article on the association between obesity and periodontal disease was published in 1977, when Perlstein et al. observed that the level of bone resorption is higher in obese rats than in the normal ones. A study reported by NHANES III (The Third National Health and Nutrition Examination Survey) showed that there is a significant correlation, in adults, between obesity and periodontal disease, the most relevant being the waist-hip ratio, followed by BMI, mass without fat and subcutaneous fat. There is evidence according to which there is a connection between metabolic syndrome and periodontal disease, as well as an increasingly relevant connection between abdominal obesity, hypertension, resistance to insulin, high plasmatic fibrinogen and high reactive protein $\mathrm{C}$. These arguments reinforce the idea that periodontal diseases and systemic diseases which are linked to obesity are based on an inflammatory mechanism associated with disorders of the lipids metabolism $[5,6]$.
Obesity is a significant predictor of periodontal disease, and resistance to insulin seems to mediate this correlation. Researchers consider that adipocytes at the level of the fat tissue have an impact on the levels of pro-inflammatory mediators, producing a state of hyperinflammation which can increase the risk of periodontal disease and resistance to insulin $[7,8]$.

Some studies have indicated that maintaining a normal weight by regular physical activity is associated with lower periodontitis prevalence. $[6,9]$ Individuals who pursued regular exercise have lower plasma levels of inflammatory markers, such as IL-6 and C-reactive protein (CRP), and show an increased insulin sensitivity that may beneficially affect periodontal health [10]. A study that analyzed the NHANES-III study population demonstrated that individuals who maintained a normal weight, pursued regular exercise, and consumed a diet in conformity with the Dietary Guidelines for Americans and the Food Guide Pyramid recommendations were $40 \%$ less likely to have periodontitis [11, 12].

The purpose of the study consists in evaluating the periodontal clinical parameters in obese patients diagnosed with chronic periodontitis, before and after surgical treatment of obesity through the procedure called gastric sleeve (GS), considered to be a risk factor in the severity of periodontal diseases.

\section{Experimental part}

Our study consists of a group of 38 patients who were investigated between October 2017 and April 2018. The ages of the patients were between 21 and 62 years, with a percentage of $69.2 \%$ of female patients, and $30.7 \%$ of male ones. The smoking patients represented $17.9 \%$ of the cases. Diseases associated with high blood pressure, diabetes

\footnotetext{
* email:drm_ion@yahoo.com,; Phone: 0758677077
} 


\begin{tabular}{|l|l|l|}
\hline BMI $\left(\mathrm{kg} \mathrm{m}^{-2}\right)$ & WHO classification & Popular description \\
\hline$<18.5$ & Underweight & Thin \\
\hline $18.5-24.9$ & $\bullet$ & Healthy, normal \\
\hline $25.0-29.9$ & Grade 1 overweight & Overweight \\
\hline $30.0-39.9$ & Grade 2 overweight & Obesity \\
\hline$\geq 40.0$ & Grade 3 overweight & Morbid obesity \\
\hline
\end{tabular}

mellitus or osteoporosis are only some of the pathologies which are secondary to obesity and were present in $76.9 \%$ of the patients included in the study.

Patients initially diagnosed with morbid obesity who were surgically treated by gastric sleeve surgery at the Surgery Department II of the County Emergency Clinical Hospital Tirgu Mures. All subjects completed the questionnaire with independent variables: age, education, socio-economic status, oral hygiene habits, smoking habit, presence of any systemic diseases.

Questionnaire. The questionnaire is a descriptive instrument specifically designed to evaluate sociodemographic characteristics including age, gender, marital status, income and years of education. Participants' history of chronic disease includong diabetes, hypertension, and dyslipidaemia were collected. Smoking was defined as current smoker, past smoker, or non-smoker.

Anthropometric measurements. Anthropometric measurements including body mass index (BMI) and waist circumference (WC) were measured. According to WHO guidelines, obesity was defined as BMI $\geq 30 \mathrm{~kg} / \mathrm{m}^{2}$ and overweight was defined as BMI between 25 and $29.9 \mathrm{~kg} /$ $\mathrm{m}^{2}$ (WHO 1998) (table 1).

Surgical procedure. As operating technique, longitudinal gastrostomy implies vertical, subtotal resection of the stomach, performed in parallel and along a small gastric pouch. This procedure can be carried out through laparotomy or laparoscopic procedure.

Clinical examination. The periodontal status was recorded on Ramfjord teeth, which include the maxillary right first molar, the maxillary left central incisor, the maxillary left first premolar, the mandibular left first molar, the mandibular right central incisor, and the mandibular right first premolar. Periodontal examination included: plaque index $(P I)$, gingival index (GI), probing depth (PD), clinical attachment level (CAL). Periodontitis was defined as presence of four or more teeth with one site or more with $P P D \geq 4 \mathrm{~mm}$ and $\mathrm{CAL} \geq 3 \mathrm{~mm}$.

Patients with pre-operative and post-operative consultion at 3 months and 6 months respectively in which either periodontal index were index of plaque, index of probing depth and index of bleeding on probing.

Correlations between periodontal clinical indexes (PD, $\mathrm{PI}, \mathrm{BOP})$ were calculated before and after gastric sleeve at 3 and 6 months respectively. Probing depth (PD) periodontal index - periodontal trench depth and inflammation stage. In order to be appreciated, the keratinization index is used, which is calculated as follows: number of keratinized cells / total number of cells evaluated.

Statistical analysis. The Statistical Package for Social Sciences (SPSS) was used for data processing. The statistical analysis was carried out using t-test and chisquare. The level of significance was set at $p<0.05$.

\section{Results and discussions}

The results of the present study provide evidence that there is an association between overweight/obesity and periodontal infection, nonetheless the strength of the association may be underestimated due the heterogenecity of the studies

A statistically significant increase in mean PD was observed at 6 months after the bariatric surgery. Mean PD reduction in the recorded sites at 6 months was $5.1 \pm 0.5 \mathrm{~mm}$ (Figure1).

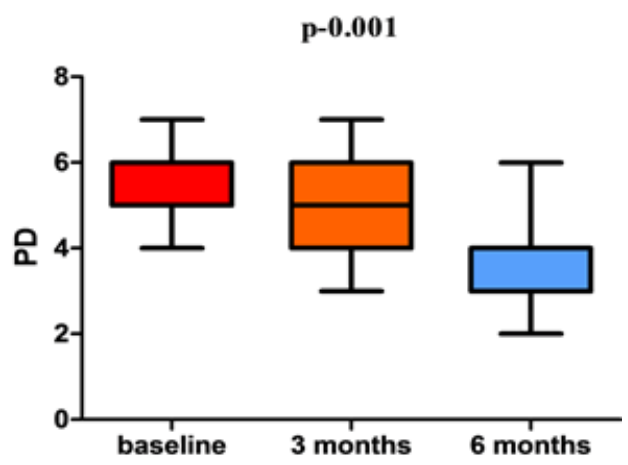

Fig. 1. Values of PD at baseline, 3 and 6 months

The bleeding on probing index (BOP) reveals a complete decrease in postoperative bleeding time. Patients at 3 months experience minor bleeding during testing and no longer showing bleeding at 6 months.

The average BOP, PI, GI, PPD, CAL, average of percent of sites with $C A L \geq 3 \mathrm{~mm}$, and percent of sites with $\mathrm{CAL} \geq 4 \mathrm{~mm}$ were significantly higher after 3 and 6 months. (Figure 2, 3).

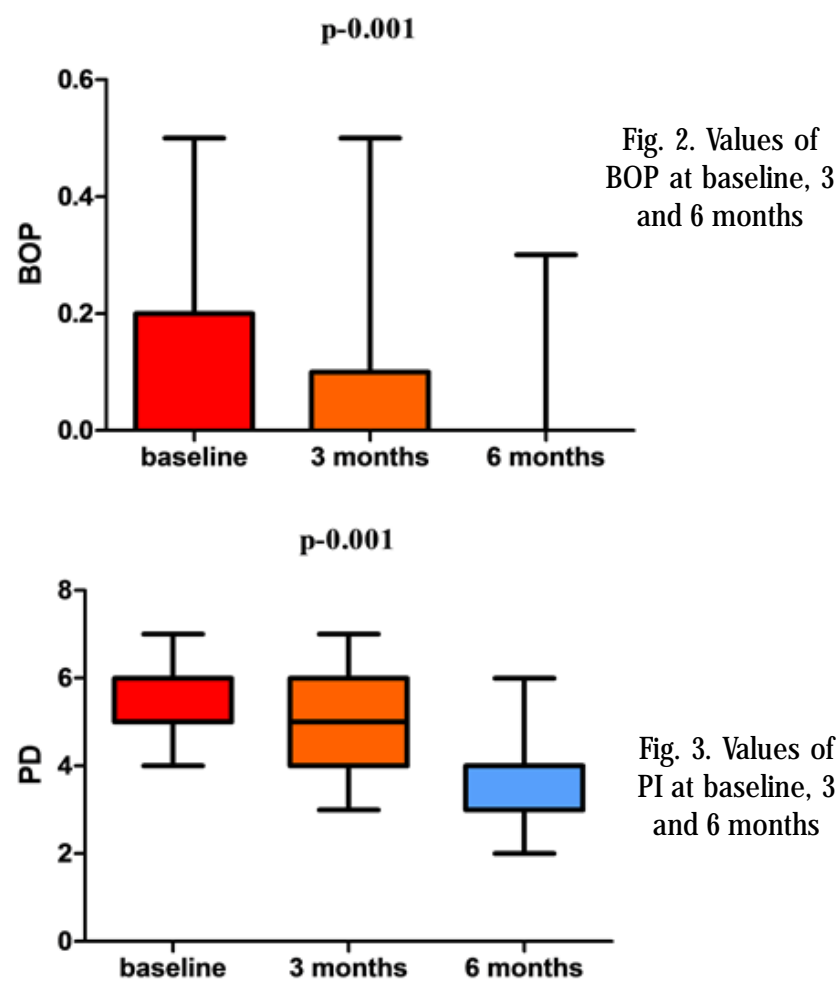


Obesity is a significant predictor of periodontal disease, and resistance to insulin seems to mediate this correlation. Researchers consider that adipocytes at the level of the fat tissue have an impact on the levels of pro-inflammatory mediators, producing a state of hyperinflammation which can increase the risk of periodontal disease and resistance to insulin $[5,10]$.

A large number of studies were carried out to get an overview of the association between obesity and periodontal disease. In 2005, CFD Vecchia etal., evaluated the relationship between overweight, obesity and periodontitis and found that obesity was significantly associated with periodontitis in adult and non-smoker women. However, overweight was not significantly associated with periodontitis [13].

In their research work, Genco et al., concluded that obesity is associated with high plasma levels of TNF- $\alpha$ and its soluble receptors, which in turn may lead to a hyperinflammatory state increasing the risk for periodontal disease $[14,15]$. A study on metabolic disorders related to obesity and periodontal disease concluded that the association among periodontal disease, diabetes and obesity confounds each other [7]. An epidemiologic study on obesity and periodontitis in 60-70-year-old men found a positive correlation between obesity and periodontal disease [16].

Sarlati et al., conducted a study on the relationship between obesity and periodontal status in a sample of young Iranian adults and found that the overall and abdominal obesity were associated with the extent of periodontal disease and hence prevention and management of obesity may be an additional factor for improving periodontal health $[17,18]$. A study on a young Japanese adult population concluded that BMI could be a potential risk factor for periodontitis among healthy young individuals i.e. those with BMI of less than $30 \mathrm{~kg} / \mathrm{m}^{2}$ [19].

Khader et al., did a study on the association between periodontal disease and obesity among adults in Jordan and came to the conclusion that BMI, high waist circumference and high fat percentage were significantly associated with increased odds of having periodontitis [7]. In Copenhagen city, an inverse relation between obesity and clinical attachment level and a slight association between BMI and bleeding on probing was found [20-22].

Boesing etal., (2009) conducted a study on the interface between obesity and periodontitis with emphasis on oxidative stress and inflammatory response and found obesity to participate in the multifactorial phenomenon of occurrence of periodontitis through the increased production of reactive oxygen species [23].

Tandon etal., found that patients of chronic generalized periodontitis who were offered periodontal therapy showed improvement in the various lipid parameters except high density lipoproteins-cholesterol, which was not significantly altered. Chronic periodontitis in otherwise healthy individuals may therefore, be contributing to the systemic inflammatory burden in these patients and adversely altering the lipid profile $[24,25]$.

Dentists may wonder what their role should be in the management of obesity and obesity-related diseases like diabetes and atherosclerosis. The diagnosis of such patients is in the realm of physicians. But a dentist can evaluate patients for signs and symptoms of obesity-related diseases. Mathus-Vliegen et al., documented that obesity is related to several aspects of oral health, such as dental caries, periodontitis and xerostomia [26]. Dentists should have ample knowledge of the signs, symptoms and diagnostic tests for metabolic syndrome and related diseases. The most common oral manifestations of diabetes are burning mouth syndrome, candidiasis, dental caries, and glossodynia, and periodontal manifestations includes multiple gingival and periodontal abscesses, inflammatory gingival enlargements, deep periodontal pockets, gingival polyps and mobile teeth [27-30].

Dentist should refer their overweight and obese periodontal patient for weight reduction interventions like diet therapy, behavioral therapy, pharmacotherapy and surgical procedures, so that they can have better control over periodontal inflammation. In the future, if obesity is to be acknowledged as a multiple-risk-factor syndrome for overall and oral health, general and oral risk assessment in the dental office should include the evaluation of BMI on a regular basis.

Based on the above, the hypothesis of this study is that life-course epidemiology has an important role in understanding the possible association of nutritional status and periodontal disease in later life. Accordingly, prospective studies are required to verify the sequence of events in the life course that may affect the development of chronic oral conditions. Such investigations could provide basis for the most appropriated time to start preventive strategies in order to reduce disease occurrence and severity, saving public resources and improving the quality of life of individuals and populations.

It is rather difficult to state whether obesity predisposes an individual to periodontal disease or the periodontal disease affects the lipids metabolism, or both. Additional studies are necessary in order to approach the problem of causality and to determine whether obesity is a real factor in the development of periodontal diseases, especially among the younger population. If this aspect is proven as being true, the prevention of periodontal diseases could be included in the intervention campaigns planned for the prevention of diseases associated with obesity. Furthermore, the prevention and management of obesity could be a complementary approach for the improvement of periodontal health [31-33].

One of the possible mechanisms which might explain a link between obesity and periodontitis includes liver disorders [34, 35], the fact that the adipose tissue secretes pro-inflammatory cytokine which can be molecules that engages the pathogenesis of these diseases. The association between IMC and the tumour necrosis factor$\alpha$ (TNF- $\alpha$ ) in the fluid of the gingival portion suggests that the TNF-á in this fluid is derived from the adipose tissue in the obese patients [36, 37]. Moreover, it has been suggested that there is an increase in the serous level of interleukin 6 and resistin, both secreted as adipocytes and associated with periodontitis. Furthermore, Haffajee and Socransky noticed an excessive increase in Tannerella forsythia in subgingival biofilms in obese patients who were periodontally healthy, which might represent, for them, a risk in the development of periodontitis. This aspect suggests that there is a possible connection between obesity and periodontitis [38, 39].

\section{Conclusions}

The results of the present systematic review provide evidence that there is an association between overweight/ obesity and periodontal infection, nonetheless the strength of the association may be underestimated due the heterogenecity of the studies. Thus, all health professionals, including the dental team, can provide to education, prevention and treatment for obese patients about the risk of periodontal diseases. There is a link between obesity and periodontitis, however the risk factors that aggravate these diseases should be clarified to elucidate the direction 
of this association. Nevertheless, oral health care measures should be implemented to obese patients.

Further prospective studies are needed to address the question of causality and to determine if obesity is a true risk factor for periodontal disease, especially among the younger population. If this proves to be the case, periodontal disease prevention could be included in planned intervention campaigns designed to preventobesity-related diseases. Conversely, the prevention and management of obesity may be an adjunctive approach to improving periodontal health.

\section{References}

1.NGUYEN D. M., EL-SERAG H.B. The epidemiology of obesity. Gastroenterol Clin North Am. 2010;39(1):1-7.

2.TARCEA ,M., FAZAKAS, Z., SZUCS, V., et. al. Mean dietary fiber intake of romanian adults - results of a survey questionnaire, Rev. Chim.(Bucharest), 68, no. 9, 2017, p. 2083-2087.

3.SAMASCA G, SUR G, LUPAN I et al. Celiac disease as an autoimmune condition, Centr. Eur J Immunol, 39(3):396-399

4.BALINT, I, NEMES-NAGY, E, CSIBI, M., et al. The role of diet and lifestyle habits in prevention of cardiovascular disease in Moldavian and Transylvanian population, Rev Chim (Bucharest), 68, no. 7, 2017, p. $1460-1465$

5.GAZIANO J. M. Fifth phase of the epidemiologic transition: the age of obesity and inactivity. JAMA. 2010; 303(3):275-6.

6.*** World Health Statistics. World Health Organization, Geneva 2008. 7.HANCU N, ROMAN G, VERESIU I.A. Diabetul zaharat, nutritia si bolile metabolice. Cluj-Napoca: Echinox, 2010:155-22.

8.MARTIN K.A, MANI MV, MANI A. New targets to treat obesity and the metabolic syndrome. Eur J Pharmacol. 2015; 763(Pt A):64-74.

9.KOH KK, PARK SM, QUON MJ . Leptin and cardiovascular disease: response to therapeutic interventions. Circulation 2008 J une 24;117(25).

10.BASSETT DR JR, WYATT HR, THOMPSON H, et al. PedometerMeasured Physical Activity and Health Bejaviors in United States Adults. Med Sci Sports Exerc.2010 Mar 16. [Epub ahead of print].

11.SINHA R, JASTREBOFF AM. Stress as a commonrisk factor for obesity and addiction. Biol Psychiatry. 2013 May 1;73(9):827-35.

12.TRAVERSY G, CHAPUT JP. Alcohol Consumption and Obesity: An Update. Curr Obes Rep. 2015 Mar;4(1):122-30.

13.BAYON V, LEGER D, GOMEZ-MERINO D, et al. Sleep debt and obesity. Ann Med. 2014 Aug;46(5):264-72.

14.BRAY GA. How do we get fat?: An epidemiological and metabolic approach. In Bray GA. The Metabolic Syndrome and Obesity, Humana Press 2007, p. 31-66.

15.YUMUK V, TSIGOS C, FRIED M, et al. European Guidelines for Obesity Management in Adults. Obes Facts. 2015;8(6):402-24.

16.OH CM, JUN JK, SUH M. Risk of cancer mortality according to the metabolic health status and degree of obesity. Asian Pac J Cancer Prev. 2014;15(22):10027-31.

17.COLON-GONZALEZ F, KIM GW, LIN JE, et al. Obesity pharmacotherapy: what is next? Mol Aspects Med.2013;34(1):71-83.

18.BENAIGES D, GODAY A, PEDRO-BOTET J, et al. Bariatric surgery: to whom and when? Minerva Endocrinol.2015 Jun;40(2):119-28.

19.BUCHWALD H. The evolution of metabolic/bariatric surgery. Obes Surd.2014 Aug;24(8):1126-35.
20.DUMITRIU HT, DUMITRIU S, DUMITRIU AS. Tratat de Parodontologie. Viata medicala Romaneasca, 2015:256-45.

21.MARIOTTI A, HEFTI AF. Defining periodontal health. BMC Oral Health. 2015; 15 Suppl 1:S6.

22.WADIA R. Periodontal disease in general practice-an update on the essentials. Dent Update. 2014;41(5):467-9.

23.KELLER A, ROHDE JF, RAYMOND K, et al. Association between periodontal disease and overweight and obesity: a systematic review. J Periodontol. 2015 Jun;86(6):766-76.

24.LEVINE RS. Obesity, diabetes and periodontitis-a triangular relationship? Br Dent J. 2013 J ul;215(1):35-9.

25.*** FactStats: Obesity and overweight. Centers for Disease Control and Prevention Web site. http://www.cdc.gov/nchs/fastats/overwt.html. Accessed Fevruary 18,2014.

26.SOLOMOU S, KORBONITS M. The role of ghrelin in weightregulation disorders: implications in clinical practice. Hormones (Athens). 2004;13(4):458-75.

27.LINDEN G, PATTERSON C, EVAN A, et al. Obesity and peridontitis in 60-70 years old men. J clin Periodontol. 2007;34:461-6.

28.PERLESTEIN MI, BISSADA NF. Influence of obesity and hypertension on theseverity of periodontitis in rats. Oral Surg Oral Med Oral Pathol. 1977:43:707-19.

29.SARLATI F, AKHONDI N, ETTEHADT, NEYESTANI T, etal. Relationship between obesity and periodontitis status in sample of young Iranian adults. Int Dent J. 2008;58:36-40.

30.SABAU, R, ORMENISAN, A, MONEA, A, SZEKELY, M, COSARCA ,A, IONESCU, T.P, BERESESCU, G, DALAI, C.E, Effect of Essential Oil Mounthwah on Halitosis, Rev. Chim. (Bucharest), 68, no. 3,2017, p. 518-521

31.KHADER YS, BAWADY HA, HARIUN TF, etal. The association between periodontal disease and obesity among adults in Jordan. Clin Periodontol. 2009;36:18-24.

32.BOESING F, PATINO JS, DA SILVA VRG, et al. The interface between obesity and periodontitis emphasis on oxidative stress and inflammatory response. Obes Rev. 2009;10:290-7.

33.TENDON S, DHINGRA MS, LAMA AK, el al. Effect of periodontal therapy on serum lipid levels. Indian J Med Specialities. 2010:1:19-25. 34.ORMENISAN, A., BALMOS, A., GOLU, M. V., TEMISTOCLE, D. B., BALDEAN, A., Tegla, E., Torok Arpad \& Beresescu, G.Is There a Relationship Between Obesity and Periodontal Diseases? Rev. Chim. (Bucharest), 69, no.10, 2018, p. 2652-2654.

35.SHAKRUKH K, ROSLAN S, RATHNA DV, et al. Prevalence of chronic periodontitis in an obese population: a preliminary study. BMC Oral Healt.2015;15:114.

36.MATHUS-VLIEGEN EM, NIKKEL D, BRAND HS. Oral aspect of obesity. Int Dent J . 2007:57:249-56.

37.NEAGOE RM, MURESAN M, BANCU S, BALMOS I, BAISAN V, VOIDAZAN S, SALA D. Results of Laparoscopic Sleeve Gastrectomy-5Year Follow-Up Study in an Eastern European Emerging Bariatric Center. Obes Surg. 2017 Apr;27(4):983-989.

38.DAHIYA P, KAMAL R, GUPTA R. Obesity, periodontal and general health: Relationship and management. Indian J Endocrinol Metab. 2012; 16(1):88-93.

39.GUSTAVO GN, FABIO RL, MARCOS BC, et al. Relatonship between periodontal disease and obsesity: the role of life-course events.Braz. Dent. J. 2014;25:16-23.

Manuscript received: 10.01 .2019 